\title{
Results of Radiation Therapy (RT) for Primary Extranodal Lymphoma of the Head and Neck: RT Techniques and Literature Review
}

\section{Aruna Turaka*}

Department of Radiation Oncology, Allegheny Health Network, Pittsburgh, PA, USA

${ }^{*}$ Corresponding author: Aruna Turaka, M.D, Assistant Professor, Department of Radiation Oncology, Temple University School of Medicine, Allegheny Health Network, 320 East North Avenue, Pittsburgh, PA-15212, USA, Tel: 412-359-3400; Fax: 412-359-3981; E-mail: aturaka@wpahs.org

Received date: May 19 2015; Accepted date: June 06 2015; Publication date: June 122015

Copyright: (c) 2015 Turaka A. This is an open-access article distributed under the terms of the Creative Commons Attribution License; which permits unrestricted use; distribution; and reproduction in any medium; provided the original author and source are credited.

\begin{abstract}
Radiation therapy (RT) is an important treatment modality for extra-nodal lymphoma (ENL) of the head and neck $(\mathrm{H} \& \mathrm{~N})$. Intensity Modulated radiation therapy (IMRT) has been shown to be associated with decrease in the incidence of late side effects in squamous cell carcinoma of the H\&N region. The purpose of the study is to determine the treatment outcomes and late toxicities in 14 patients with ENL of H\&N treated with two different RT techniques. Median age was 60 years (range: 42-95). Median follow up was 28 months (range: 1-52). Thirteen patients were treated with RT (8 with IMRT) while one patient with chemotherapy only. Majority of the patients had stage I disease $(64 \%)$. Overall response rate after combined modality treatment was $100 \%$. There were no local or neck node relapses and none with grade 3 or 4 toxicities. Radiation therapy following chemotherapy or used alone was associated with better local and distant disease control and IMRT is associated with less toxicity profile compared with conventional radiotherapy techniques.
\end{abstract}

Keywords: Extranodal lymphoma; Head and neck; Radiation therapy; IMRT

\section{Introduction}

Squamous cell carcinoma of head and neck $(\mathrm{H} \& \mathrm{~N})$ region is the most common histologic malignancies; followed by lymphomas [1]. In 2012; there were an estimated 79; 190 new cases of lymphoma (9;060 Hodking's disease; HD; 70;130 non-Hodgkin's lymphoma; NHL) and 20;130 estimated deaths from lymphoma for all sites [2].

The estimated new cases from oral cavity and pharynx were 40;250; larynx 12;360; eye and orbit 2;610; and thyroid 56;460. This represents an equal incidence of lymphomas and carcinomas in the H\&N region. Vast majority of literature supports the use of newer modalities for the treatment of $\mathrm{H} \& \mathrm{~N}$ squamous cell carcinoma including advanced radiation therapy techniques [3]; new chemotherapeutic agents [4]; biological agents [5]; molecular markers [6]; function imaging methods [7]; and trans-oral robotic surgery compared with ENL of $\mathrm{H} \& \mathrm{~N}$ [8]. Extranodal lymphomas (ENL) can present at gastric; nongastric; cutaneous; and $\mathrm{H} \& \mathrm{~N}$ regions.

They are associated with autoimmune conditions; human immunodeficiency virus (HIV); immunodeficiency syndromes; infection; or chronic inflammatory disorders. The clinical presentation and prognosis $[9,10]$ of ENL-NHL varies with the site of presentation.

These are most commonly seen in Asia [11,12] than in North America. NHL is the more common than HD including the most common diffuse large B cell type; marginal zone lymphoma; maltassociated lymphoid tissue (MALT) [13]. H\&N is the the most common site for extra-nodal lymphoma; especially non-hodgkins lymphoma (NHL); which presents $25 \%$ extranodally [14]. Head and neck NHL compromise 33\% of all extranodal sites [15] and can present in Waldeyer ring; para-nasal sinuses; nasopharynx; oral cavity; layrnx; thyroid; and rarely salivary gland [12].
Combination of chemotherapy and radiation therapy [16,17] provides better local control rates for ENL. Addition of radiation therapy has been show to improve local control rates in the published series $[16,18]$.

Intensity Modulated radiation therapy (IMRT) has been shown for head and neck cancers to be associated with decreased late side effects like xerostomia and dysphagia [19]. Also; IMRT provides better dose coverage compared to $3 \mathrm{D}$ conformal treatment plans with less normal tissue doses [20].

The purpose of the study is to determine the clinico-pathological features; treatment outcomes and late toxicities in patients with ENL of head and neck ENL patients treated with IMRT.

\section{Materials and Methods}

This is a single institution; retrospective review of records from 2007-2010. Institute review board (IRB) approval was obtained for the retrospective study. A total of 14 patients with ENL of the H\&N were treated at our institution during this time period.

Orbital lymphoma cases were excluded. All patients underwent complete staging work-up for lymphoma. Pre and post-treatment 18 Fluoro-Deoxy Glucose (18FDG-PET) scan was done in 50\% of the patients (Figure 1). Chemotherapy was given at the discretion of treating medical oncologist. 13 patients were eligible RT. Majority of the patients $(\mathrm{N}=8)$ were treated with IMRT.

Descriptive data of diagnostic and treatment factors were obtained for all patients. Overall; local relapse free survivals were obtained via Kaplan-Meier estimation method. All the analyses were performed using the statistical analysis systems (SAS institute; Cary; NC). Acute and late toxicity were recorded as per the Radiation Therapy Oncology Group (RTOG) toxicity criteria [21]. 


\section{Pre - RT}

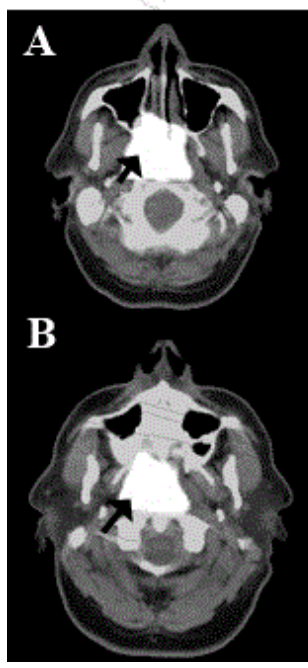

\section{Post-RT}

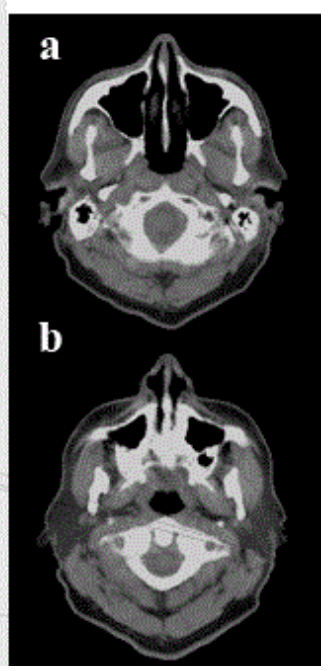

Figure 1: A representative patient treated with RT with NHL of nasopharynx imaged with $[18 \mathrm{~F}]$ Fluorodeoxyglucose (FDG)Positron Emission Tomography (PET). A and B are two representative slices pre-RT treatment while $\mathrm{a}$ and $\mathrm{b}$ are the corresponding slices post-RT. The mass was FDG avid at SUV of 22.2 (black arrow) and corresponded to a soft tissue mass on CT (Figure 2). The patient had complete resolution by 10 months with no increased SUV on the PET.

\section{Results}

Patient characteristics are shown in Table 1 . The median age of the patient was 60 years (range: 42-95). Median follow up was 28 months (range:1-52). There were equal females and males and 7 were smokers. Tables 2 and 3 shows the tumor characteristics and radiation treatment characteristics. Most common sites for primary disease were 2 nasopharynx; 2; paranasal sinuses; 4 oropharynx; 3 oral cavity and 3 other sites. Majority of the patients had stage I disease (9 patients; $64 \%$ ) with a mixture of histological subtypes. Three patients were stage II ( 2 non-bulky; one with bulky disease) and 2 were stage IV with presence of H\&N- ENL. Diffuse large B cell (DLBCL); 4 patients and mucosa associated lymphoid tissue (MALT); 3 patients; were common histological variants. Twelve patients had CD20 (cluster designation) positive NHL. One patient had nodular Hodgkin's disease involving the base of tongue; CD15; CD30 positive. She was a 50 year old woman with stage IIEA disease and treated with 4 cycles of ABVD (adriamycin; bleomycin; vinblastine and dacarbazine) chemotherapy followed by involved field radiation therapy (IFRT) to the primary and bilateral neck nodes to a dose of 20 Gy in 10 fractions; using 200 cGy per fraction over 2 weeks duration.

Bone marrow biopsy was negative except for one patient. Thirteen patients were treated with radiation therapy while 1 patient with chemotherapy only. Median RT dose was 3600 cGy (range: 2000-6000) with involved field radiation treatment (IFRT); 180-200 cGy per fraction; 5 days a week over 4-5 weeks duration. IMRT was used for 8 patients (62\%). Median of seven fields was used for IMRT treatment planning. Four patients did not receive any form of chemotherapy. Five patients received R-CHOP (Rituximab; Cyclophosphamide; Adriamycin; Vincristine; Prednisone); 1 R-CDOP; 1 CHOP; 1 Rituximab alone and 1 with ABVD. There was no evidence of FDG avid lesion noted on post-treatment PET scan (Figures 1 and 2). There were no local or neck node relapses. One DLBCL patient had systemic relapse involving stomach and bilateral testes and was treated with second-line chemotherapy and radiation therapy. The 91 year old patient (Table 3; patient 5) with stage IE DLBCL was treated with 4 cycles of R-CDOP and IFRT relapsed in inguinal lymph node and right breast. Another patient had relapse in liver. All patients tolerated the treatment very well without any grade 3 or 4 acute/late RTOG toxicities. The most common toxicities were taste change (Grade 1 and 2; 83\%); skin changes (Grade 1 and 2; 75\%); and xerostomia (Grade 1 and $2 ; 67 \%$ ). None of the patients developed grade 3 xerostomia (both acute and late). Late grade 2 xerostomia was seen in patients treated with conventional RT but not with IMRT. The overall response rate after combined modality treatment was $100 \%$. The 2-year disease free survival is $88 \%$ for RT patients. The 2 -year actuarial survival rate was $80 \%$. All patients were clinically free of disease at last follow up with 12 out of 14 patients alive.

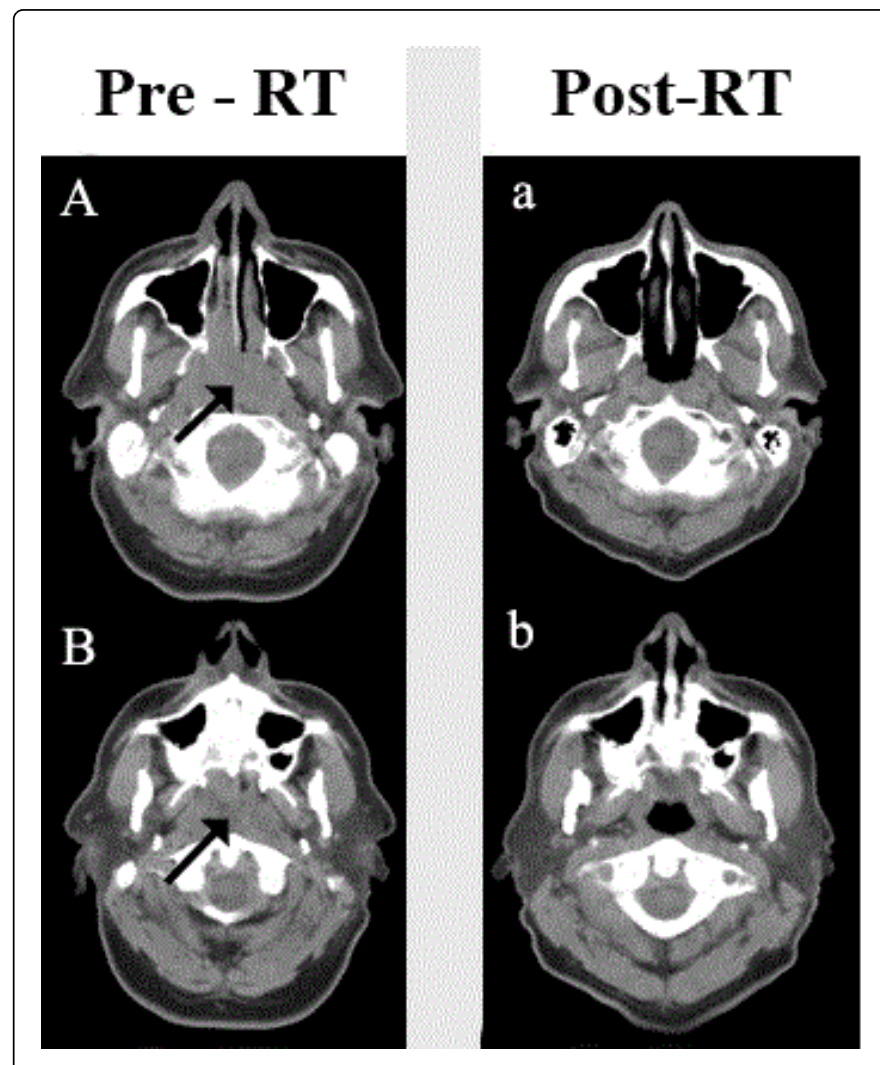

Figure 2: A representative patient treated with RT with NHL of nasopharynx imaged with CT. A and B are two representative slices pre-RT treatment while $\mathrm{a}$ and $\mathrm{b}$ are the corresponding slices postRT. This picture corresponds to PET scan seen in Figure 1. The patient had complete resolution by 10 months seen in CT scan. 
Citation: Turaka A (2015) Results of Radiation Therapy (RT) for Primary Extranodal Lymphoma of the Head and Neck: RT Techniques and Literature Review. J Nucl Med Radiat Ther 6: 232. doi:10.4172/2155-9619.1000232

\begin{tabular}{|c|c|c|}
\hline \multicolumn{2}{|l|}{ Age; median (range) in years } & 60 (42-95) \\
\hline \multicolumn{3}{|l|}{ Gender; N (\%) } \\
\hline & Males & $7(50)$ \\
\hline & Females & $7(50)$ \\
\hline \multicolumn{3}{|l|}{ Race; N (\%) } \\
\hline & White & $12(86)$ \\
\hline & Chinese & $1(7)$ \\
\hline & African-American & $1(7)$ \\
\hline \multicolumn{3}{|l|}{ Smoking history; N (\%) } \\
\hline & Yes & $7(50)$ \\
\hline & No & $7(50)$ \\
\hline \multicolumn{3}{|l|}{ Alcohol history; N (\%) } \\
\hline & Yes & $6(43)$ \\
\hline & No & $8(57)$ \\
\hline \multicolumn{2}{|l|}{ Follow-up; median (range) in months } & $28(1-52)$ \\
\hline
\end{tabular}

Table 1: Patient characteristics $(\mathrm{N}=14)$.

\begin{tabular}{|c|c|c|}
\hline \multicolumn{3}{|l|}{ Ann Arbor Staging; N (\%) } \\
\hline & Stage I & $9(64)$ \\
\hline & Stage II & $3(21)$ \\
\hline & Stage III & $0(0)$ \\
\hline & Stage IV & $2(14)$ \\
\hline \multicolumn{3}{|l|}{ Histology } \\
\hline & NK-T cell lymphoma & $1(7)$ \\
\hline & Diffuse large B-cell lymphoma & $1(7)$ \\
\hline & Large B-cell lymphoma & $1(7)$ \\
\hline & Large cell lymphoma; burkitts & $1(7)$ \\
\hline & Low grade lymphoma; atypical lymphoma cells & $1(7)$ \\
\hline & MALT & $3(21)$ \\
\hline & Diffuse large B cell lymphoma & $4(29)$ \\
\hline & Follicular lymphoma & $1(7)$ \\
\hline & Nodular sclerosis; HD & $1(7)$ \\
\hline \multicolumn{3}{|c|}{ Chemotherapy regimen; $\mathbf{N}(\%)$} \\
\hline & ABVD & $1(7)$ \\
\hline & $\mathrm{CHOP}$ & $1(7)$ \\
\hline
\end{tabular}


Citation: Turaka A (2015) Results of Radiation Therapy (RT) for Primary Extranodal Lymphoma of the Head and Neck: RT Techniques and Literature Review. J Nucl Med Radiat Ther 6: 232. doi:10.4172/2155-9619.1000232

\begin{tabular}{|c|c|c|}
\hline & R-CHOP & $5(36)$ \\
\hline & R-CDOP & $1(7)$ \\
\hline & Rituxan & $2(14)$ \\
\hline & None & $4(29)$ \\
\hline \multicolumn{3}{|l|}{ Radiation technique; N (\%) } \\
\hline & IFRT & $12(86)$ \\
\hline & 3D-CRT & $1(7)$ \\
\hline & None & $1(7)$ \\
\hline \multicolumn{3}{|l|}{ Total radiation dose in Gy; $\mathbf{N}(\%)$} \\
\hline & 2000 & $1(7)$ \\
\hline & 2975 & $1(7)$ \\
\hline & 3000 & $1(7)$ \\
\hline & 3600 & $7(50)$ \\
\hline & 4000 & $1(7)$ \\
\hline & 4500 & $1(7)$ \\
\hline & 6000 & $1(7)$ \\
\hline & None & $1(7)$ \\
\hline
\end{tabular}

Table 2: Tumor/treatment characteristics $(\mathrm{N}=14)$.

\begin{tabular}{|c|c|c|c|c|c|c|c|c|}
\hline S. No & Age (Year) & Gender & Histology & Stage & Treatment Method & $\begin{array}{l}\text { RT dose } \\
\text { (cGy) }\end{array}$ & Chemotherapy & $\begin{array}{l}\text { Status at last } \\
\text { visit }\end{array}$ \\
\hline 1 & 42 & M & Follicular lymphoma & IA & RT & 2975 & None & NED \\
\hline 2 & 65 & M & $\begin{array}{l}\text { Diffuse large B cell } \\
\text { lymphoma }\end{array}$ & IAE & IFRT + Chemo & 3600 & $\mathrm{R}-\mathrm{CHOP}$ & NED \\
\hline 3 & 56 & M & $\begin{array}{l}\text { Diffuse large B cell } \\
\text { lymphoma }\end{array}$ & IAE & IFRT + Chemo & 3600 & $\mathrm{R}-\mathrm{CHOP}$ & $\begin{array}{l}\text { Failure at testes } \\
\text { and stomach }\end{array}$ \\
\hline 4 & 66 & M & MALT & IAE & IFRT & 3600 & None & NED \\
\hline 5 & 91 & $\mathrm{~F}$ & $\begin{array}{l}\text { Diffuse large B cell } \\
\text { lymphoma }\end{array}$ & IE & IFRT + Chemo & 3600 & R-CDOP & $\begin{array}{l}\text { Failure at left } \\
\text { inguinal } L N \text { and } \\
\text { right breast }\end{array}$ \\
\hline 6 & 61 & $\mathrm{~F}$ & $\begin{array}{l}\text { Diffuse large B cell } \\
\text { lymphoma }\end{array}$ & IIBE & IFRT + Chemo & 3600 & $\mathrm{R}-\mathrm{CHOP}$ & NED \\
\hline 7 & 50 & $\mathrm{~F}$ & $\begin{array}{l}\text { Nodular sclerosis; } \\
\text { HD }\end{array}$ & IIAE & IFRT + Chemo & 2000 & $A B \vee D$ & NED \\
\hline 8 & 68 & $M$ & $\begin{array}{l}\text { Diffuse large B-cell } \\
\text { lymphoma }\end{array}$ & IAE & IFRT + Chemo & 3600 & R-CHOP & NED \\
\hline 9 & 59 & $\mathrm{~F}$ & $\begin{array}{l}\text { Large cell lymphoma; } \\
\text { burkitts }\end{array}$ & IV & IFRT + Chemo & 3600 & $\mathrm{R}-\mathrm{CHOP}$ & NED \\
\hline 10 & 95 & M & $\begin{array}{l}\text { Low grade } \\
\text { lymphoma; atypical } \\
\text { lymphoma cells }\end{array}$ & IAE & IFRT + Chemo & 4500 & Rituxan & NED \\
\hline
\end{tabular}


Page 5 of 6

\begin{tabular}{|l|l|l|l|l|l|l|l|l|}
\hline 11 & 56 & F & MALT & IV & Chemo only & Not treated & Rituxan & NED \\
\hline 12 & 49 & M & NK-T cell lymphoma & IAE & IFRT + Chemo & 6000 & CHOP & Failure in liver \\
\hline 13 & 55 & F & MALT & IAE & IFRT & 3000 & None & NED \\
\hline 14 & 72 & F & $\begin{array}{l}\text { Large } \\
\text { lymphoma }\end{array}$ & IIAE & IFRT & 4000 & None & NED \\
\hline
\end{tabular}

RT: Radiation Therapy; cGy: Centi Gray; NED: No Evidence Of Disease; M: Male; F: Female; LN: Lymph Node; chemo: Chemotherapy; HD: Hodgkin's Disease; E: Extranodal

Table 3: Individual Patient Characteristics $(\mathrm{N}=14)$.

\section{Discussion}

Our study found that radiation therapy with the use of IMRT following chemotherapy or used alone in ENL of head and neck was associated with local and distant disease control in the majority of patients with a toxicity profile that appears favorable compared with conventional radiotherapy techniques. Hoederath et al. evaluated long-term outcomes in 63 patients with limited state (stage I and IIE) primary ENL of $\mathrm{H} \& \mathrm{~N}$ region treated with definitive radiation therapy [18]. Low-grade stage I and II tumors were treated to a dose of $30 \mathrm{~Gy}$ (2 Gy per fraction) with same RT technique used to treat the epithelial tumors and high grade tumors were treated to $50 \mathrm{~Gy}$ after 4 cycles of CHOP chemotherapy. The 5 year progression-free survival (PFS) and overall survival (OS) rates for low-grade tumors were 54\%; 67\%; and for high-grade tumors were $68 \%$ and $88 \%$; respectively. They recommended incorporating radiotherapy after chemotherapy to obtain better cure rates for these patients. Prognosis was influenced by histological variant in the series. Pasini et al. from Italy reviewed the outcomes of 71 patients with H\&N ENL treated with combined modality therapy including surgery; RT alone (n:21); and chemotherapy followed by radiation therapy (n:42) [16]. Disease related survival and disease free survival were better for combined modality therapy $(92 \% ; 72 \%)$ compared with RT alone (81\% and $43 \%)$. Most of the patients who received chemotherapy were high-grade histology. A 20-year retrospective experience on combined modality ENL of H\&N region was published by Hanna et al among 98 patients were different hisologic subtypes [17]. Low-grade lymphoma with stage I and II were treated with radiation therapy alone. The overall and disease free survival rates for all patients were $60 \%$ and $50 \%$ respectively. In a study by Ezzat et al. 130 patients with Waldeyer's ring NHL with stage I and II were treated with chemotherapy alone; RT alone; and combined modality therapy [22]. There was no difference in complete response rate between the 3 modalities. The relationship between tumor control and radiation therapy was studied by MacDermed from Stanford University in 40 patients with indolent ENL of H\&N [23]. RT resulted in significantly higher rates of freedom from progression (at 5-years; $90 \%$ versus $34 \%$ for patients with and without radiotherapy; p:0.001) and freedom from local progression (at 5 -years; $100 \%$ versus $72 \%$ for patients with and without radiotherapy; p:0.006) in early-stage patients. This is the first study to use IMRT to review the decrease in toxicities of extranodal lymphoma located in head and neck area. In our series; all patients had CR after completion of RT and combined modality treatment with an overall response rate of $100 \%$. The 2 -year actuarial survival rate was $80 \%$. IMRT was found in head and neck cancers to be extremely useful in salivary gland sparing [19]. We found that toxicities were limited to grade 1 and 2 toxicities with a majority of patients having taste change and skins changes.

The majority of our cases were NHL which is consistent with findings in other studies [24]. Many of these patients were diagnosed with Stage I-II lymphoma; which is consistent with previous studies [25]. This could be the main reason that these patients did so well with radiation and chemotherapy.

The limitations of this study are that it is retrospective in nature including only small series of patients. Also; extranodal lymphoma is rare in cancer treatment. Thus; accrual takes an extensive number of years $[14,25]$. However; it may be necessary to use larger studies are required to confirm that IMRT is as effective as involved-field RT using conventional RT techniques.

\section{Limitations of the study}

It is a single institution experience of small series of cases. Patients were treated with different RT techniques based on the discretion of the treating physician. The details of RT parameters and the dosimetric variables were not available to archive from the records. Long-term follow up is needed to describe the details regarding the late normal tissue toxicities.

\section{Conclusions}

IMRT following chemotherapy or used alone in ENL of head and neck was associated with local and distant disease control in the majority of patients; with toxicity profile that appears favorable compared with conventional radiotherapy techniques. Creating multiinstitutional database with support from grants by the governmental agencies will also enable to formulate the guidelines for these rare tumors.

\section{References}

1. Urquhart A, Berg R (2001) Hodgkin's and non-Hodgkin's lymphoma of the head and neck. Laryngoscope 111: 1565-1569.

2. Siegel R, Naishadham D, Jemal A (2012) Cancer statistics, 2012. CA Cancer J Clin 62: 10-29.

3. Bhide SA, Nutting CM (2010) Advances in radiotherapy for head and neck cancer. Oral Oncol 46: 439-441.

4. Bhide SA, Nutting CM (2010) Advances in chemotherapy for head and neck cancer. Oral Oncol 46: 436-438.

5. O'Rorke MA, Ellison MV, Murray LJ, Moran M, James J, et al. (2012) Human papillomavirus related head and neck cancer survival: A systematic review and meta-analysis. Oral Oncol 48: 1191-1201. 
Citation: Turaka A (2015) Results of Radiation Therapy (RT) for Primary Extranodal Lymphoma of the Head and Neck: RT Techniques and Literature Review. J Nucl Med Radiat Ther 6: 232. doi:10.4172/2155-9619.1000232

Page 6 of 6

6. Sawicki M, Szudy A, Szczyrek M, Krawczyk P, Klatka J (2012) Molecularly targeted therapies in head and neck cancers. Otolaryngol Pol 66: 307-312.

7. Zips D, Zöphel K, Abolmaali N, Perrin R, Abramyuk A, et al. (2012) Exploratory prospective trial of hypoxia-specific PET imaging during radiochemotherapy in patients with locally advanced head-and-neck cancer. Radiother Oncol 105: 21-28.

8. Weinstein GS, O'Malley BW Jr, Magnuson JS, Carroll WR, Olsen KD, et al. (2012) Transoral robotic surgery: a multicenter study to assess feasibility, safety, and surgical margins. Laryngoscope 122: 1701-1707.

9. Arican A, Dinçol D, Akbulut H, Onur H, Demirkazik A, et al. (1999) Clinicopathologic features and prognostic factors of primary extranodal non-Hodgkin's lymphomas in Turkey. Am J Clin Oncol 22: 587-592.

10. Economopoulos T, Fountzilas G, Kostourou A, Daniilidis J, Pavlidis N, et al. (1998) Primary extranodal non Hodgkin's lymphoma of the head and neck in adults: a clinicopathological comparison between tonsillar and non tonsillar lymphomas. (Hellenic co-Operative Oncology Group). Anticancer Res 18: 4655-4660.

11. Al Diab AR, Aleem A, Qayum A, Al Askar AS, Ajarim DS (2011) Clinicopathological pattern of extranodal non-Hodgkin's lymphoma in Saudi Arabia. Asian Pac J Cancer Prev 12: 3277-3282.

12. Assanasen T, Wannakrairot $P$, Keelawat S, Pramprayoon N, Chaipipat M (2004) Extranodal malignant lymphoma of the upperaerodigestive tract in King Chulalongkorn Memorial Hospital according to WHO classification. J Med Assoc Thai 87 Suppl 2: S249-254.

13. Economopoulos T, Papageorgiou S, Dimopoulos MA, Pavlidis N, Tsatalas C, et al. (2005) Non-Hodgkin's lymphomas in Greece according to the WHO classification of lymphoid neoplasms. A retrospective analysis of 810 cases. Acta Haematol 113: 97-103.

14. Etemad-Moghadam S, Tirgary F, Keshavarz S, Alaeddini M (2010) Head and neck non-Hodgkin's lymphoma: a 20-year demographic study of 381 cases. Int J Oral Maxillofac Surg 39: 869-872.

15. Economopoulos T, Asprou N, Stathakis N, Papageorgiou E, Dervenoulas J, et al. (1996) Primary extranodal non-Hodgkin's lymphoma in adults: clinicopathological and survival characteristics. Leuk Lymphoma 21: 131-136.
16. Pasini F, Cetto GL, Todeschini G, Di Marco A, Verlato G, et al. (1997) Combination of chemotherapy and radiotherapy improves the cure rate in primary extranodal lymphomas of the head and neck (PLHN). Anticancer Res 17: 2837-2842.

17. Hanna E, Wanamaker J, Adelstein D, Tubbs R, Lavertu P (1997) Extranodal lymphomas of the head and neck. A 20-year experience. Arch Otolaryngol Head Neck Surg 123: 1318-1323.

18. Hoederath A, Sack H, Stuschke M, Lampka E (1996) [Radiotherapy of primary extranodal non-Hodgkin's lymphoma of the head and neck region. Results of a prospective multicenter study. Study Group NHL: early studies]. Strahlenther Onkol 172: 356-366.

19. Bhide SA, Newbold KL, Harrington KJ, Nutting CM (2012) Clinical evaluation of intensity-modulated radiotherapy for head and neck cancers. Br J Radiol 85: 487-494.

20. Tomita N, Kodira T, Tachinbana H, Nakaruma T, Nakahara R, et al. (2009) A comparison of radiation treatment plans using IMRT with helical tomotherapy and $3 \mathrm{D}$ conformal radiotherapy for nasal natural killer/T-cell lymphoma. Br J Radiol 82: 756-763.

21. Rubin P, Constine LS, Fajardo LF, Phillips TL, Wasserman TH (1995) RTOG Late Effects Working Group. Overview. Late Effects of Normal Tissues (LENT) scoring system. Int J Radiat Oncol Biol Phys 31: 1041-1042.

22. Ezzat AA, Ibrahim EM, El Weshi AN, Khafaga YM, AlJurf M, et al. (2001) Localized non-Hodgkin's lymphoma of Waldeyer's ring: clinical features, management, and prognosis of 130 adult patients. Head Neck 23: 547-558.

23. MacDermed D, Thurber L, George TI, Hoppe RT (2004) Le Q-T: Extranodal nonorbital indolent lymphomas of the head and neck: relationship between tumor control and radiotherapy. International Journal of Radiation Oncology Biology Physics 59: 788-795.

24. Iyengar P, Mazloom A, Shihadeh F, Berjawi G, Dabaja B (2010) Hodgkin lymphoma involving extranodal and nodal head and neck sites: characteristics and outcomes. Cancer 116: 3825-3829.

25. Chi HS, Lee KW, Chiang FY, Tai CF, Wang LF, et al. (2012) Head and neck extranodal lymphoma in a single institute: a 17 -year retrospective analysis. Kaohsiung J Med Sci 28: 435-441. 